\title{
Semipolar GaN-based laser diodes for Gbit/s white lighting communication: devices to systems
}

Changmin Lee, Chao Shen, Clayton Cozzan, Robert M. Farrell, Shuji Nakamura, et al.

Changmin Lee, Chao Shen, Clayton Cozzan, Robert M. Farrell, Shuji Nakamura, Ahmed Y. Alyamani, Boon S. Ooi, John E. Bowers, Steven P. DenBaars, James S. Speck, "Semipolar GaN-based laser diodes for Gbit/s white lighting communication: devices to systems," Proc. SPIE 10532, Gallium Nitride Materials and Devices XIII, 105321N (23 February 2018); doi: $10.1117 / 12.2315791$

SPIE. Event: SPIE OPTO, 2018, San Francisco, California, United States 


\title{
Semipolar GaN-based laser diodes for Gbit/s white lighting communication: devices to systems
}

\author{
Changmin Lee*a ${ }^{\text {a }}$, Chao Shen ${ }^{\mathrm{b}}$, Clayton Cozzan ${ }^{\mathrm{a}}$, Robert M. Farrell ${ }^{\mathrm{c}}$, Shuji Nakamura ${ }^{\mathrm{a}}$, Ahmed Y. \\ Alyamani $^{\mathrm{d}}$, Boon S. Ooi ${ }^{\mathrm{b}}$, John E. Bowers ${ }^{\mathrm{a}}$, Steven P. DenBaars ${ }^{\mathrm{a}}$, and James S. Speck ${ }^{\mathrm{a}}$ \\ ${ }^{a}$ Materials Department, University of California, Santa Barbara, CA, USA 93106 \\ ${ }^{b}$ Photonics Laboratory, King Abdullah University of Science and Technology (KAUST), Thuwal, \\ Saudi Arabia 21534 \\ ${ }^{c}$ Department of Electrical and Computer Engineering, University of Wisconsin-Madison, Madison, \\ WI, USA 53706 \\ ${ }^{\mathrm{d}}$ King Abdulaziz City of Science and Technology (KACST), Riyadh, Saudi Arabia 11442
}

\begin{abstract}
We report the high-speed performance of semipolar GaN ridge laser diodes at $410 \mathrm{~nm}$ and the dynamic characteristics including differential gain, damping, and the intrinsic maximum bandwidth. To the best of our knowledge, the achieved modulation bandwidth of $6.8 \mathrm{GHz}$ is the highest reported value in the blue-violet spectrum. The calculated differential gain of $\sim 3 \times 10^{-16} \mathrm{~cm}^{2}$, which is a critical factor in high-speed modulation, proved theoretical predictions of higher gain in semipolar GaN laser diodes than the conventional $c$-plane counterparts. In addition, we demonstrate the first novel white lighting communication system by using our near-ultraviolet (NUV) LDs and pumping red-, green-, and blueemitting phosphors. This system satisfies both purposes of high-speed communication and high-quality white light illumination. A high data rate of $1.5 \mathrm{Gbit} / \mathrm{s}$ using on-off keying $(\mathrm{OOK})$ modulation together with a high color rendering index (CRI) of 80 has been measured.
\end{abstract}

Keywords: GaN, Laser diodes, visible light communication, modulation, gain, solid-state lighting, phosphors, Li-Fi

\section{INTRODUCTION}

GaN-based optoelectronic devices have shown great usefulness for many years in various applications such as general illumination, automotive lighting, traffic signs, displays, and optical data storage. For these conventional applications, the main development has been focused on high-efficiency and high-power operation. Recently, there has been an great interest in the communication capability for emerging technologies such as smart lighting, remote sensing, underwater wireless optical communication (UWOC), plastic fiber optic communication, and vehicle-to-vehicle communication. One of the rapid developing technologies is the indoor visible light communication (VLC), which is also known as lightfidelity (Li-Fi). ${ }^{1}$ It is highly motivated by the saturation of spectral efficiency in conventional radio frequency (RF) communication due to dramatically growing mobile data demands. Even though GaAs- and InP-based optoelectronic technologies are already mature in the telecommunication spectrum, the uniqueness of both ultraviolet (UV) and visible spectra from $\mathrm{GaN}$ materials can offer new solutions to various issues and specific advantages: a broad range of unregulated spectrum, no electromagnetic interference (EMI), high security, and high efficiency.

Light-emitting diodes (LEDs) have been popularly used as a VLC transmitter to satisfy the purpose of both illumination and communication. ${ }^{2}$ Early VLC studies used commercial LED chips. However, the comparatively large chip size $(0.1 \sim$ $1 \mathrm{~mm}^{2}$ ) of high-power designed LEDs is associated with significant RC parasitic effects, leading to a modulation bandwidth of only a few MHz. The obvious solution is downsizing the device dimensions to $10 \sim 100 \mu \mathrm{m}$ to avoid large $\mathrm{RC}$ parasitic effects. Significant improvement was first reported with a micro-sized LED ( $\mu$ LED) design offering modulation bandwidth up to $245 \mathrm{MHz}$ of the single pixel emitting at $450 \mathrm{~nm} .{ }^{3}$ Later, more progress broke the records up to $1 \mathrm{GHz}$ by optimizing device configuration and quantum well design to reduce the carrier lifetime. ${ }^{4-6}$ Studies using

*changminlee86@gmail.com; ssleec.ucsb.edu 
semipolar/nonpolar crystal orientations also reported $1 \mathrm{GHz}$ bandwidths by taking the advantage of the reduced polarization-induced electric field offering low carrier lifetimes and high modulation bandwidths. ${ }^{7,8}$

Superluminescent diodes (SLDs) are attractive light emitters exhibiting the advantages of speckle noise-free, high output power, and spatial coherence. In addition, SLDs can be high-speed transmitters, overcoming LED limitations. Relatively high modulation bandwidths can be achieved by fast carrier recombination from amplified spontaneous emission. Recent work has demonstrated SLDs with different designs and reported the highest modulation bandwidth up to $800 \mathrm{MHz}$, which is comparable with $\mu$ LEDs. ${ }^{9}$

Laser diodes (LDs) have been the most popular transmitter for emerging telecommunication technologies. Properties, including spatial coherence, narrow spectral linewidth, compactness, and high modulation bandwidth, make LDs exceptionally suitable for both fiber optic and free space communication. Furthermore, the high perfection of the GaAsand InP-based material systems boosted the development of more advanced devices such as distributed Bragg reflector (DBR), distributed feedback (DFB) lasers, and vertical cavity surface emitting lasers (VCSELs). Even though GaAs- and InP-based telecommunication transmitters cover a wide range of the spectrum from $650 \mathrm{~nm}(\mathrm{AlGaInP} / \mathrm{GaAs})$ to $1650 \mathrm{~nm}$ (InGaAsP/InP), shorter wavelengths below $600 \mathrm{~nm}$ require GaN-based material systems. Previously, most GaN LDs were developed for data storage, automotive lighting, medical, and projector applications. Recently, many studies have reported LD-based solid-state lighting by taking an advantage of high output power and an absence of efficiency droop at high current density. ${ }^{10}$ With the advent of VLC and Li-Fi applications, GaN LDs now gain more momentum as a data transmitter since communication capabilities were already proven in other III-V systems. Researchers reported the modulation bandwidths of $1.4 \mathrm{GHz}$ and $2.6 \mathrm{GHz}$ with on-off keying (OOK) data rates of $2.5 \mathrm{Gbit} / \mathrm{s}$ and $4 \mathrm{Gbit} / \mathrm{s}$ using commercial LDs emitting at $422 \mathrm{~nm}$ and $450 \mathrm{~nm}$, respectively. ${ }^{11,12}$ These results imply that LDs without any optimization for communication have higher bandwidths than other reported VLC transmitters such as $\mu$ LED and SLDs. Red, green, and blue (RGB) lasers were modulated to increase the data rate ( $>10 \mathrm{Gbit} / \mathrm{s})$ as well as generate white light with higher modulation schemes such as wavelength division multiplexing (WDM) and orthogonal frequency division multiplexing (OFDM) ${ }^{13,14}$ More practical approaches for white light communication were reported by using different color converters (typically phosphors). Even though the response in LEDs suffers from comparatively slow relaxation lifetimes of phosphors, LDs with phosphors have shown OOK data rates of $2 \mathrm{Gbit} / \mathrm{s}$ without significant negative effects from the color converting process. ${ }^{15,16}$ Many advantageous merits of LDs over LEDs point to the need for more advanced studies of LDs for VLC.

Here, we discuss the high-speed properties of edge-emitting InGaN/GaN quantum well (QW) LDs grown on a semipolar crystal orientation comprising a novel laser-based white lighting communication system. At first, we give an overview of the fundamental difference of modulation limits in LEDs and LDs and the benefits of semipolar/nonpolar GaN for modulation capability. Then, device results and analysis for semipolar near-ultraviolet (NUV) edge-emitting LDs, followed by extracting important parameters. Finally, we demonstrate a NUV laser-based data transmission system by utilizing red-, green-, and blue-emitting phosphors offering Gbit/s data rates as well as high color rendering index (CRI).

\section{FUNDAMENTALS OF MODULATION FOR LASERS AND LEDS}

Typical LED chips for solid-state lighting are designed with large emission areas from $0.1 \mathrm{~mm}^{2}$ to $1 \mathrm{~mm}^{2}$ to generate high optical output power for illumination. However, for communication purposes, since the capacitance scales with device area, the modulation bandwidth is typically limited by RC parasitic effects. ${ }^{2,8}$ For $\mu$ LEDs, which are optimized to minimize parasitic effects, the optical response and modulation bandwidth are mainly determined by the differential carrier lifetime $(\tau)$ described by: ${ }^{17}$

$$
\tau=\frac{1}{A+2 B n+3 C n^{2}}
$$

where $n$ is the carrier density in the QWs and A, B, and C are the Shockley-Read-Hall nonradiative, radiative, and Auger recombination coefficients, respectively. From the relationship (1), the differential carrier lifetime is inversely proportional to the carrier density in the QWs corresponding to the injected current. But the differential carrier lifetime is saturated at high carrier density due to combined effects, such as phase space filling. ${ }^{18}$ Thus, the carrier lifetime of typical LEDs can be reduced on the order of ns, while the shortest reported value of $\mu$ LEDs is $0.1 \sim 0.2$ ns with the advantage of operating at high current density. ${ }^{4,18}$ The highest reported bandwidths in QW LEDs are saturated near 1 $\mathrm{GHz}(\mathrm{GaN})$ and $1.7 \mathrm{GHz}(\mathrm{GaAs}) .{ }^{4,6,7,19}$ 
For LDs, the behavior of photons in the cavity is directly coupled to the injected carriers due to the stimulated emission. Thus, the small signal response can be derived from the following two rate equations in terms of injected carrier density and photon density in the cavity: $:^{20}$

$$
\begin{gathered}
\frac{d n}{d t}=\frac{\eta_{i} I}{q V}-\frac{n}{\tau}-v_{g}\left(g_{t h}+\frac{d g}{d n} \Delta n\right) s \\
\frac{d s}{d t}=\Gamma v_{g}\left(g_{t h}+\frac{d g}{d n} \Delta n\right) s-\frac{s}{\tau_{p}}
\end{gathered}
$$

where $s$ is the photon density in the active region, $\eta_{i}$ is the injection efficiency, $I$ is the injected current, $q$ is the electron charge, $V$ is the volume of the active layer, and $\tau$ and $\tau_{p}$ are the carrier and photon lifetimes, respectively. $v_{g}$ is the group velocity, $\Gamma$ is the optical confinement factor, and $g_{t h}$ is the threshold material gain. Under small signal conditions, a small fluctuation of gain is added onto the threshold gain by multiplying the differential gain, $d g / d n$, by the fluctuation in carrier density, $\Delta n$. The spontaneous emission that is coupled into the lasing mode is ignored far above the threshold for this modulation condition. The small signal modulation for both carriers and photons is proportional to a secondorder transfer function $\left(H(\omega)=\omega_{R}^{2} /\left(\omega_{R}^{2}+\omega^{2}+j \omega \gamma\right)\right.$ ), where $\omega_{R}$ is the relaxation resonance frequency (or $f_{R}=$ $\left.\omega_{R} / 2 \pi\right)$ and $\gamma$ is the damping factor. Since the modulation bandwidth can be estimated from the resonance frequencies in low damping regime, analyzing the resonance and damping characteristics is important for high-speed capabilities: ${ }^{20}$

$$
\omega_{R}^{2} \approx \frac{v_{g} s \frac{d g}{d n}}{\tau_{p}}=\frac{\Gamma v_{g} \frac{d g}{d n}}{q V} \eta_{i}\left(I-I_{t h}\right)
$$

Different from the first order transfer function of the response of LEDs, the LDs have a second harmonic transfer function with a resonance due to strong coupling of the carriers and the photons. After the onset of lasing, the stimulated emission is the dominant process for photon generation rather than spontaneous emission, and the fast photon lifetime turns to be the main limiting factor for modulation bandwidth of LDs. Even though gain compression typically occurs before reaching the photon lifetime limit, typical reported bandwidths are above several $\mathrm{GHz}$ with the highest reported edge emitting LDs up to $30 \mathrm{GHz}$ in GaAs and InP LDs. ${ }^{21,22}$

\section{HIGH SPEED SEMIPOLAR LASER DIODES: DEVICES}

For GaN-based LDs, the most preferred crystal orientation is polar (0001) c-plane because this is the established orientation for LED and now large area bulk c-plane substrates, produced by hydride vapor phase epitaxy (HVPE), are widely available. LDs grown on $c$-plane GaN suffer from polarization-induced electric fields, leading to shifted electron and hole wave-functions. ${ }^{23,24}$ Also, a high density of states (DOS) due to the balanced biaxial in-plane strain causes relatively high threshold current densities. Semipolar and nonpolar LDs have been predicted to have higher optical gain than $c$-plane LDs due to a higher wave-function overlap, a reduction in the density of states via separation of the three valence bands and natural dipole emission. ${ }^{25-27}$ Recent studies have shown significant improvements in high-power performance and lower threshold current densities of semipolar/nonpolar LDs. ${ }^{28-32}$ It is also expected to have high modulation bandwidth and high-speed performance for semipolar/nonpolar LDs due to higher differential gain and lower threshold current density as shown in Eq. (5).

NUV LDs were grown on a bulk GaN semipolar $(20 \overline{2} \overline{1})$ substrate by atmospheric pressure (AP) metalorganic chemical vapor deposition (MOCVD). As shown in Fig. 1(a), the epitaxial structure consists of a $1 \mu \mathrm{m}$ Si-doped $n$-GaN cladding layer, a $500 \mathrm{~nm} n^{+}$-GaN high doped top-side contact layer $\left([\mathrm{Si}]=5.2 \times 10^{19} \mathrm{~cm}^{-3}\right)$, a $350 \mathrm{~nm} n$-GaN low doped layer $\left([\mathrm{Si}]=6.2 \times 10^{18} \mathrm{~cm}^{-3}\right)$ to reduce the absorption loss from high doped layer, and a $60 \mathrm{~nm} n-\operatorname{In}_{0.025} \mathrm{Ga}_{0.975} \mathrm{~N}$ waveguiding layer. The active region consisted of a 4 period undoped $\mathrm{In}_{0.1} \mathrm{Ga}_{0.9} \mathrm{~N} / \mathrm{GaN}(3.5 \mathrm{~nm} / 7 \mathrm{~nm})$ multiple quantum well (MQW), followed by a $16 \mathrm{~nm} p-\mathrm{Al}_{0.18} \mathrm{Ga}_{0.82} \mathrm{~N}$ electron blocking layer (EBL) linearly graded in composition and doping down to GaN at the topside. Then a $60 \mathrm{~nm} p-\operatorname{In}_{0.025} \mathrm{Ga}_{0.975} \mathrm{~N}$ waveguiding layer symmetric to $n$-waveguide and $600 \mathrm{~nm}$ $\mathrm{Mg}$-doped $p$-GaN cladding layer were grown followed by a $10 \mathrm{~nm}$ highly $\mathrm{Mg}$-doped $p^{+}-\mathrm{GaN}$ contact layer. The detailed optimization is discussed in a previous report by Yonkee et $a l .{ }^{33}$ 
(a)

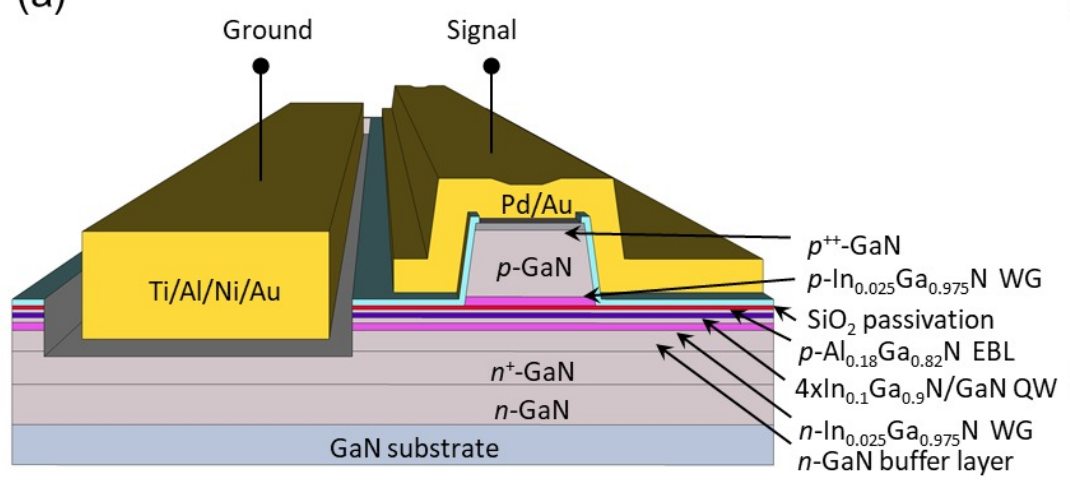

(b)

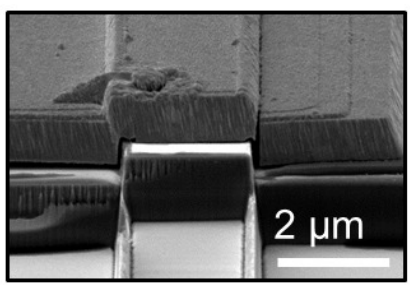

(c)

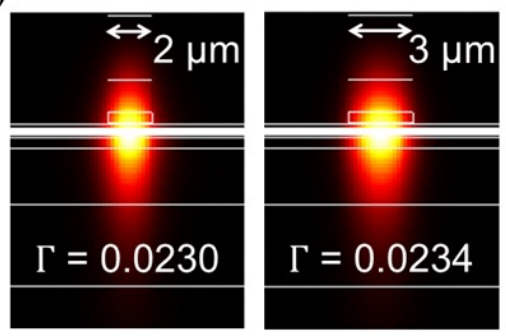

(d)

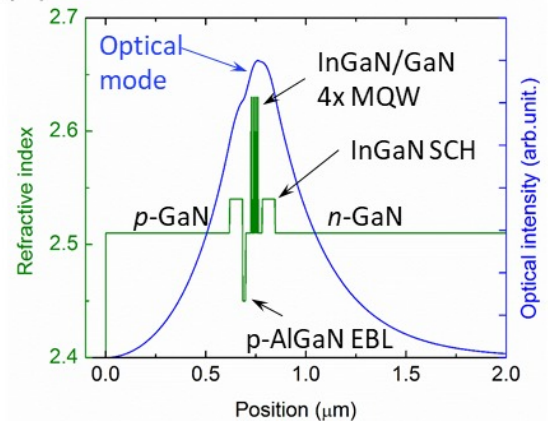

Figure 1. (a) The schematic image of ground-signal (GS) contact designed GaN laser diodes. (b) Scanning electron microscopic (SEM) image of the fabricated laser facet. (c) Simulated lateral mode for $2 \mu \mathrm{m}$ and $3 \mu \mathrm{m}$ wide of cavities and (d) longitudinal mode of designed epitaxial structure by FIMMWAVE.

After the MOCVD growth and $p$-GaN activation, the sample was first cleaned by aqua regia $\left(1: 3 \mathrm{HNO}_{3}: \mathrm{HCl}\right)$. Each step was patterned by stepper lithography. Since the ridges are narrow down to $1.5 \mu \mathrm{m}$ wide, a self-aligned process was used to form effective sidewall passivation. Ridges were formed by reactive ion etching (RIE) using $\mathrm{Cl}_{2} / \mathrm{BCl}_{3}$. As a selfaligned process, instead of stripping off the photoresist (PR), $200 \mathrm{~nm}$ of $\mathrm{SiO}_{2}$ was deposited as a passivation layer onto the field area and ridge sidewalls via sputtering, followed by lift-off on the top surface of the ridges. After wet etching a portion of the $\mathrm{SiO}_{2}$ layer by $\mathrm{HF}$, the $n$-via was etched by RIE using $\mathrm{Cl}_{2} / \mathrm{BCl}_{3}$ down to the center of a 500 -nm $n^{+}$-GaN layer to form the topside $n$-type contact. Ti/Al/Ni/Au $(15 / 100 / 100 / 100 \mathrm{~nm}) n$-contacts were deposited by an electron beam evaporator, followed by rapid thermal annealing (RTA) with an $\mathrm{N}_{2}$ ambient environment at $450{ }^{\circ} \mathrm{C}$ to lower the contact resistance. $\mathrm{Pd} / \mathrm{Au}(30 / 100 \mathrm{~nm}) \mathrm{p}$-contacts were deposited on top of the ridges, followed by common pad metals of Ti/Au $(15 / 1000 \mathrm{~nm})$ for both $p$ - and $n$-pads. Mirror facets were formed by $\mathrm{RIE}$ using $\mathrm{Cl}_{2} / \mathrm{BCl}_{3}$ and were left uncoated as shown in Fig. 1(b). Corresponding simulation for lateral and longitudinal modes was performed as shown in Fig. 1(c) and (d). The full structure is shown in Fig. 1(a).

(a)

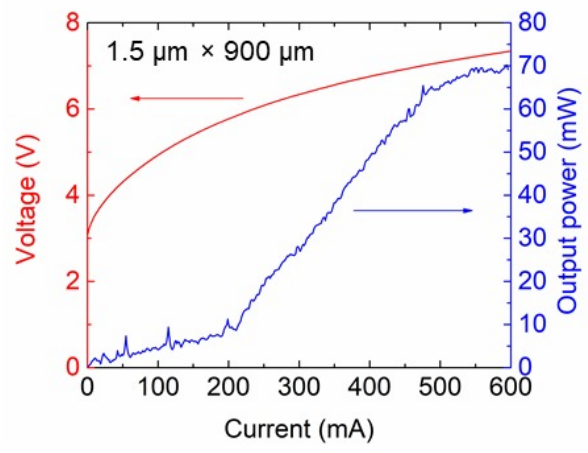

(b)

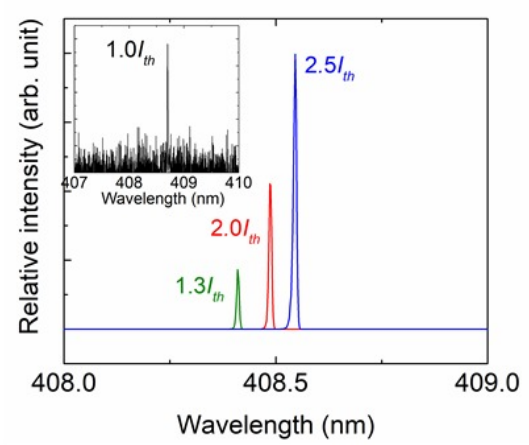

(c)

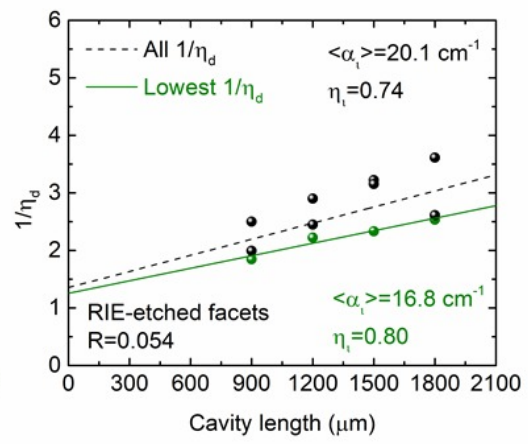

Figure 2. (a) CW light-current-voltage (LIV) characteristics of $1.5 \mu \mathrm{m} \times 900 \mu \mathrm{m}$ LD cavity. (b) Dependence of lasing spectra on different pumping current. (c) Cavity length dependent calculation for internal loss and injection efficiency from $900 \mu \mathrm{m}$ to $1800 \mu \mathrm{m}$ cavities. 
The light-current-voltage $(L-I-V)$ characteristics of the different cavities $(1.5 \mu \mathrm{m}, 2 \mu \mathrm{m}$, and $3 \mu \mathrm{m}$ wide with varying lengths from $600 \mu \mathrm{m} \sim 1800 \mu \mathrm{m}$ ) were measured to investigate the performance of the output power under $\mathrm{CW}$ operation at $20^{\circ} \mathrm{C}$. The result of $1.5 \mu \mathrm{m} \times 900 \mu \mathrm{m}$ long were representatively shown in Fig. 2(a). The large amount of spontaneous emission was obtained below threshold current since the light output was measured in the integrating sphere. The threshold current $\left(I_{t h}\right)$ and threshold current density $\left(J_{t h}\right)$ were $180 \mathrm{~mA}$ and $13.3 \mathrm{kA} / \mathrm{cm}^{2}$, respectively, with a corresponding threshold voltage $\left(V_{t h}\right)$ of $5.7 \mathrm{~V}$ under $\mathrm{CW}$ using a two-probe measurement. The spectral characteristics were measured by an optical spectral analyzer (OSA, YOKOGAWA AQ6373B) under pulsed input with a $0.5 \%$ duty cycle. The spectra of $1.5 \mu \mathrm{m} \times 900 \mu \mathrm{m}$ are shown in in Fig. 2(b). The dominant lasing peak starts near $408.7 \mathrm{~nm}$ and the cavity modes exist at $1.0 I_{t h}$ (inset of Fig. 2(b)), and the lasing peak red shifts from $1.3 I_{t h}$ to $2.5 I_{t h}$, with $10 \mathrm{pm}$ full width half maximum (FWHM), which is expected due to the resolution limit of OSA. This red shift might be due to the gain spectra shifts or band shrinkage as current increases. A calculated injection efficiency of $80 \%$ was obtained by fitting the lowest value of differential efficiency on different cavity length of LDs as shown in Fig. 2(c). Internal loss was also calculated to be $16.8 \mathrm{~cm}^{-1}$ for $\mathrm{R}=0.054$ of non-vertical facets with $6^{\circ}$ angle generated by RIE etching..$^{34,35}$

(a)

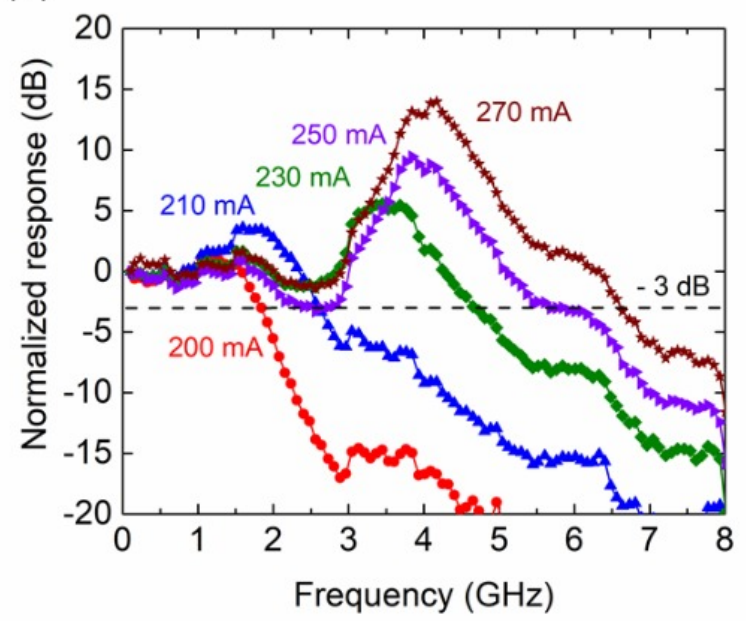

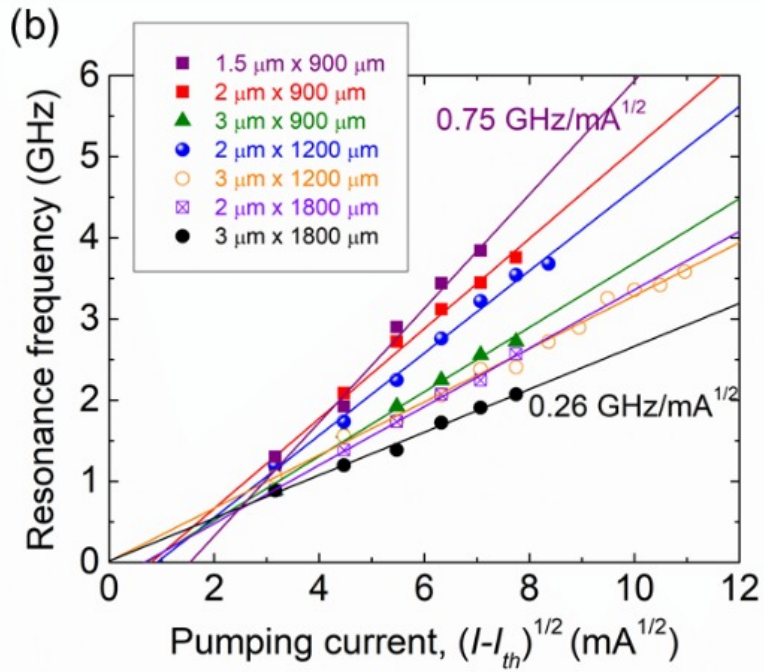

Figure 3. (a) Normalized frequency response of $1.5 \mu \mathrm{m} \times 900 \mu \mathrm{m}$ LD. (b) Dependence of resonance frequency on pumping current.

As shown in Fig. 3(a), the frequency response of the $1.5 \mu \mathrm{m} \times 900 \mu \mathrm{m}$ long LD cavity was measured using a $10 \mathrm{GHz}$ GaAs $p$-i- $n$ PD (ALPHALAS UPD-30-VSG-P), although the actual bandwidth of PD was limited to near $7 \mathrm{GHz}$ for the blue-violet spectrum. The highest measured 3-dB bandwidth of the $\mathrm{LD}$ was $6.8 \mathrm{GHz}$ at $270 \mathrm{~mA}$ of drive current. This is the limitation of the measurement setup due to the PD, not the device limit. The LD is also expected to obtain higher 3$\mathrm{dB}$ bandwidths with a higher speed PD that covers the UV-violet spectrum. To the best of the authors' knowledge, this is the highest reported modulation bandwidth in the blue-violet spectral range and of any III-nitride QW LDs. Figure. 3(b) shows the dependence of the relaxation resonance frequency on the drive current for different cavity sizes. The slopes are dependent on cavity size, not internal parameters, resulting in similar differential gains as expected. The slopes range from $0.75 \mathrm{GHz} / \mathrm{mA}^{1 / 2}$ for the largest area of the cavity to $0.26 \mathrm{GHz} / \mathrm{mA}^{1 / 2}$ for the smallest area of the cavity. Calculated differential gains are $2.3 \pm 0.5 \times 10^{-16} \mathrm{~cm}^{2}$ for different cavities by using the formula (5), mentioned in section 2 . These values are in a good agreement with the reported differential gains of other III-nitride QW LDs and even comparable with those of quantum dot (QD) and nanowire (NW) LDs. ${ }^{36-40}$ Compared to conventional polar $c$-plane LDs, the differential gain of semipolar (20 $\overline{2} \overline{1})$ LDs are expected to be higher due to the higher electron-hole wave-function overlap in the lower density of states. ${ }^{25,41,42}$ At low power operation, where gain compression is not significant, high differential gain leads to a higher $f_{\mathrm{R}}$, resulting in a higher modulation bandwidth. ${ }^{43}$ At high power, the gain compression becomes dominant effect due to high photon density in the cavity. Thus, damping factor is critical to limit the modulation bandwidth. The calculated $K$-factors were approximately $0.3 \mathrm{~ns} \sim 0.4 \mathrm{~ns}$ from the data points of three small cavities $(2 \mu \mathrm{m} \times 900 \mu \mathrm{m}, 3 \mu \mathrm{m} \times 900 \mu \mathrm{m}$, and $2 \mu \mathrm{m} \times 1200 \mu \mathrm{m})$ before RC parasitic effect occurs. From $K$-factor, the gain compression factor and intrinsic maximum bandwidth can be extracted to be $7.4 \times 10^{-17} \mathrm{~cm}^{3}$ and $27 \mathrm{GHz}$, respectively. ${ }^{20,44}$ 


\section{DEMONSTRATION OF WHITE LIGHTING COMMUNICATION SYSTEM: SYSTEMS}

Compared to white light generated using blue-emitting LDs pumping YAG:Ce phosphors, white light generated with a near ultraviolet (NUV) or violet LDs pumping red-, green-, and blue-emitting (RGB) phosphors shows expected improvements in both color rendering index (CRI) and correlated color temperature (CCT) ${ }^{10,15,45}$ Additionally, the spectral intensity of sunlight is lower in the NUV and violet spectral range than in the blue spectral range that is typically used for III-nitride emitters in solid-state lighting systems. As a result, NUV LDs enable VLC systems that can be robust in the presence of high intensities of sunlight, for example, in a room with many windows. Thus, NUV LD-based VLC is a potentially attractive approach to achieve high performance white lighting and VLC functionalities.

(a)

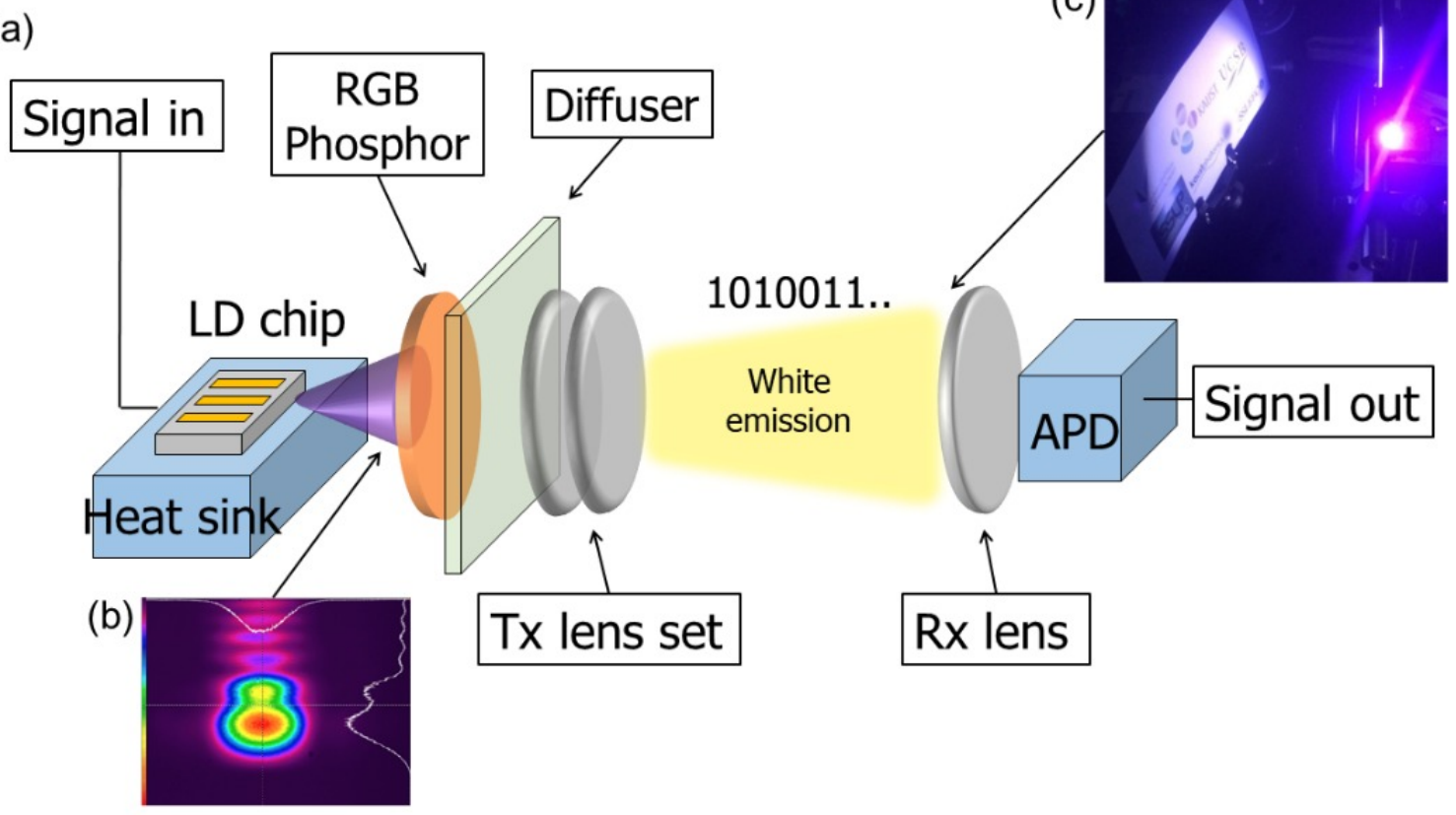

Figure 4. (a) Schematic of NUV LD-based VLC System (b) Measured beam profile of 4 um $\times 1200 \mu \mathrm{m}$ cavity NUV LD (c) A photograph of far-field white emission generated from the remote RGB phosphor pumped by the NUV LD.

The white lighting, free-space data transmission link was established by using a $409 \mathrm{~nm}$ NUV LD with RGB phosphors

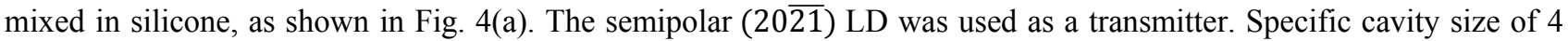
$\mu \mathrm{m} \times 1200 \mu \mathrm{m}$ having single lateral mode was chosen to generate uniform white emission as well as stable high data rate as shown in Fig. 4(b). The on-wafer LD was mounted on a microwave ground-signal (GS) probe station with a heat sink and a thermoelectric cooler (TEC). The phosphor mixture was installed in front of the LD with 1-2 cm spacing, followed by polyethylene terephthalate (PET) diffuser to provide uniform white emission. The transmitter (Tx) and receiver (Rx) lenses were properly installed to collimate the emitted beam as shown in Fig. 4(a). To investigate any effects of solar light, a $300 \mathrm{~W}$ Xenon lamp solar simulator (Enlithetch SS-F5-3A) with an illumination area of $5 \mathrm{~cm} \times 5 \mathrm{~cm}$ was installed behind the laser chip for improved coupling to the lens. Contrary to previous work, an optical blue-filter was not required in the current LD-based white lighting setup as the current LD is not significantly affected by phosphor response based on our previous investigation. ${ }^{15}$ The emitted photons are received at the $1 \mathrm{GHz}$ avalanche photodetector (APD, Menlo System APD 210), which is placed $15 \mathrm{~cm}$ from the emitted light. The reason to choose $1 \mathrm{GHz}$ APD is to collect diffused white emission at large active area rather than $10 \mathrm{GHz} p-i-n$ PD used in previous section. Excitation and emission spectra of the individual phosphors were measured using a fluorometer (Horiba) with a $15 \mathrm{~cm}$ integrating sphere (Quanta- $\phi$ ) attachment for quantum yield measurements. The white light emitted from the LD and RGB phosphor mixture was measured using an Ocean Optics HR 4000 spectrometer, and phosphor emission. 
(a)

(b)
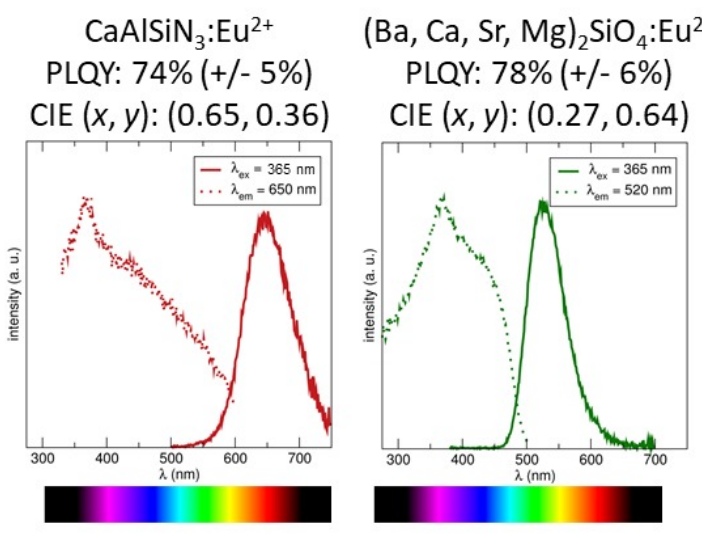

$\mathrm{BaMgAl}_{10} \mathrm{O}_{17}: \mathrm{Eu}^{2+}$ PLQY: 78\% (+/- 5\%)

PLQY: 74\% (+/- 5\%) PLQY: 78\% (+/- 6\%)

CIE $(x, y):(0.14,0.08)$

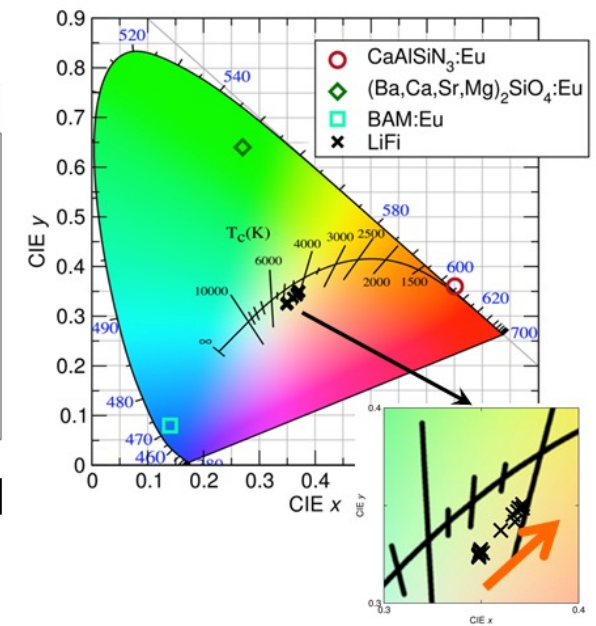

Figure 5 (a) Plots of Excitation (dotted lines) and emission (solid lines) for red- $\left(\mathrm{CaAlSiN}_{3}: \mathrm{Eu}^{2+}\right)$, green- $\left(\left(\mathrm{Ba}, \mathrm{Ca}, \mathrm{Sr}, \mathrm{Mg}_{2} \mathrm{SiO} \mathrm{O}_{4}: \mathrm{Eu}^{2+}\right)\right.$, and blue- $\left(\mathrm{BaMgAl}_{10} \mathrm{O}_{17}: \mathrm{Eu}^{2+}\right)$ emitting phosphors. (b) CIE chromaticity coordinates for $365 \mathrm{~nm}$ excitation for each phosphor (red circle for $\mathrm{CaAlSiN}_{3}: \mathrm{Eu}^{2+}$, green diamond for $\left.(\mathrm{Ba}, \mathrm{Ca}, \mathrm{Sr}, \mathrm{Mg})_{2} \mathrm{SiO}_{4}: \mathrm{Eu}^{2+}\right)$, cyan square for $\left(\mathrm{BaMgAl}_{10} \mathrm{O}_{17}: \mathrm{Eu}^{2+}\right)$, and white emission of RGB mixture excited by $409 \mathrm{~nm}$ LD (black cross for LiFi) in this system. The CIE coordinates of the LD-VLC RGB mixture for different laser currents lies close to the Planckian locus and red-shifts (decreasing coordinated color temperature) to warmer white light as drive current to the LD increases.

The excitation and emission properties of the RGB phosphors used are shown in Fig. 5(a). The red-, green-, and blueemitting phosphors are $\mathrm{CaAlSiN}_{3}: \mathrm{Eu}^{2+},(\mathrm{Ba}, \mathrm{Ca}, \mathrm{Sr}, \mathrm{Mg})_{2} \mathrm{SiO}_{4}: \mathrm{Eu}^{2+}$, and $\mathrm{BaMgAl}_{10} \mathrm{O}_{17}: \mathrm{Eu}^{2+}$ (or BAM:Eu), respectively, and were mixed in silicone in a ratio of 1:1.5:3 to achieve white emission. ${ }^{46}$ Each phosphor was separately measured for external quantum yields of $74 \%, 78 \%$, and $78 \%$, respectively and commission Internationale de l'Eclairage (CIE) chromaticity coordinates of $(0.65,0.36),(0.27,0.64)$, and $(0.14,0.08)$, respectively, as shown in Fig. 5(b). The coordinates for each phosphor create a large triangle in the CIE diagram for potential white emission. The CCT and CIE coordinates obtained by white emission of $409 \mathrm{~nm}$ NUV LD exciting RGB phosphor mixture (labeled as LiFi in Fig. 5 (b)) ranged from $4700 \mathrm{~K}$ to $4050 \mathrm{~K}$ with increasing current from $100 \mathrm{~mA}$ to $600 \mathrm{~mA}$ where the CCT is finally saturated (Fig 2b). A maximum CRI value of 80 was obtained at $500 \mathrm{~mA}$, which is significantly improved compared to the previously reported value of 58 for blue LD and yellow phosphor. ${ }^{15}$

(a)

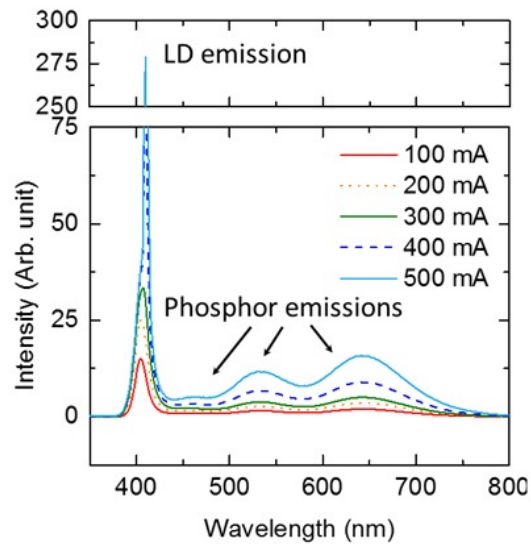

(b)

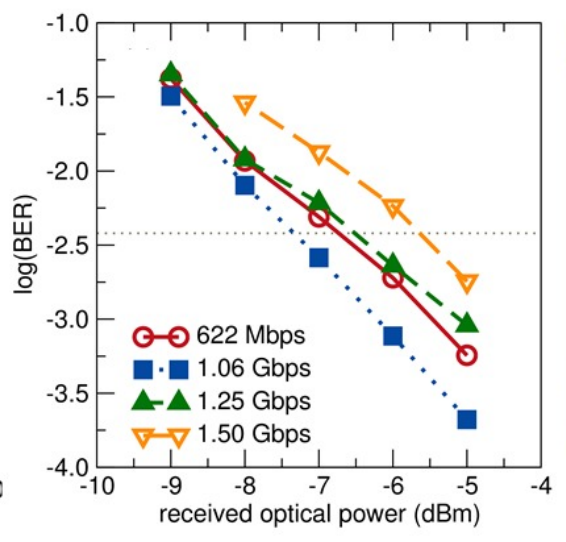

(c)

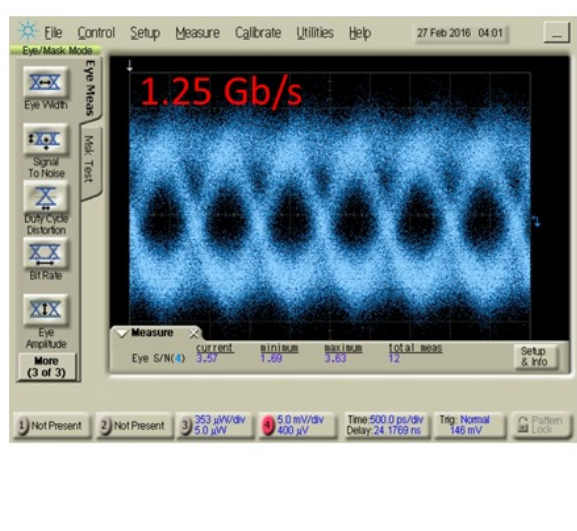

Figure 6. (a) Spectra of LD based white emission by pumping RGB phosphor. (b) BER characteristics of LD-based white light communication system using RGB phosphors at different data rates with the FEC limit (grey dotted line). (c) The eye diagram of the LD-based white light data transmission at $1.25 \mathrm{Gbit} / \mathrm{s}$. 
The spectral characteristics of the white emission is shown in Fig. 6(a). The peak of LD emission appears at $409 \mathrm{~nm}$ with only a $1 \mathrm{~nm}$ wavelength shift above the lasing threshold $(>300 \mathrm{~mA})$ with the advantage of semipolar $(20 \overline{21}) \mathrm{GaN}$. The red- and green-phosphors show peak emission wavelengths of $650 \mathrm{~nm}$ and $520 \mathrm{~nm}$, respectively. Blue phosphor emission was comparatively weak due to low absorption at $409 \mathrm{~nm}$ excitation. Increasing blue emission could be either accomplished via higher blue phosphor loading and/or higher quantum yield blue emission, which could improve device efficiency and achieve a slightly higher CRI. In addition to the quality of the white light, NUV LD-based VLC system is expected to have significant advantages in VLC since the narrow spectrum close to UV only covers lowest level of the sunlight spectrum. Thus, with a proper optical filter, the VLC system using violet or NUV LD has a higher signal-tonoise ratio (SNR) than a blue LED or LD-based VLC system.

Data transmission of non-return-to-zero (NRZ) on-off keying (OOK) modulation was performed to evaluate the data rate of NUV LD-based white light communication system. A $2^{10}-1$ of pseudo-random binary sequences (PRBS) was generated from bit error rate tester (Agilent N4903B J-BERT) to obtain both a bit error rates (BERs) and eye diagrams by using a digital communications analyzer (Agilent 86100). Figure. 6(b) shows the dependence of BERs on received optical power at different data rate including $622 \mathrm{Mbit} / \mathrm{s}, 1.06 \mathrm{Gbit} / \mathrm{s}, 1.25 \mathrm{Gbit} / \mathrm{s}$, and 1.5 Gbit/s. The BER of white light data link passes the forward error correction (FEC) criteria of $3.8 \times 10^{-3}$ at $1.5 \mathrm{Gbps}$ with a BER of $1.8 \times 10^{-3}$ as the highest achieved data rate. Since the bandwidth of APD limits the system bandwidth at $1 \mathrm{GHz}$, it is expected to achieve higher data rate than 1.5 Gbps with proper higher-speed PD. The data rate can also be improved with higher order modulation scheme such as quadrature amplitude modulation (QAM)-orthogonal frequency division multiplexing (OFDM), even though OOK modulation is typically used to show the capability of communication system. Figure. 6(c) shows a clear open eye diagram at $1.25 \mathrm{Gbit} / \mathrm{s}$ with SNR of 3.63 under the drive current of $570 \mathrm{~mA}$.

\section{CONCLUSION}

In summary, the high-speed performance of a semipolar InGaN/GaN LD emitting at $409 \mathrm{~nm}$ was reported with lasing characteristics, the modulation bandwidth, and dynamic parameters. The achieved modulation bandwidth was $6.8 \mathrm{GHz}$, which is at least 5 times higher than the highest reported modulation bandwidth of LEDs. Dynamic characteristics and internal parameters were discussed to prove the prediction of high gain in semipolar LD. High differential gain was obtained with $2.3 \pm 0.5 \times 10^{-16} \mathrm{~cm}^{2}$ improving the modulation bandwidth as well as the lasing performance. Also, the damping characteristics were studied to estimate the theoretical limit of lasing bandwidth and a modulation from gain compression and intrinsic maximum bandwidth, respectively. For the communication system, LD-based white light communication was demonstrated with a RGB phosphor mixture. The system using $410 \mathrm{~nm}$ NUV LD produced white light with a high CRI of 80 and a low CCT of $4050 \mathrm{~K}$. This is a significant improvement over previously reported systems that used blue LDs and YAG:Ce phosphors. The system is expected to have a communication merit of a lower signal-to-noise ratio than a blue laser-based VLC system due to the low background solar light. A $1.25 \mathrm{Gbit} / \mathrm{s}$ data rate with a clear open eye diagram and $1.5 \mathrm{Gbit} / \mathrm{s}$ data rate that passed FEC were obtained by using NRZ OOK modulation. Thus, NUV laser-based VLC systems can satisfy both high quality lighting and high-speed communication.

\section{ACKNOWLEDGEMENTS}

This work was funded by the KACST(SB140013)-KAUST(SB140014)-UCSB Solid State Lighting Program (SSLP) and by the Solid State Lighting and Energy Electronics Center (SSLEEC) at University of California, Santa Barbara (UCSB). A portion of this work was performed in the UCSB nanofabrication facility, part of the National Science Foundation (NSF) funded Nanotechnology Infrastructure Network (NNIN) (ECS- 0335765). This work also made use of UCSB Materials Research Laboratory (MRL) central facilities supported by the NSF MRSEC Program (DMR 1121053).

\section{REFERENCES}

[1] Haas, H., Yin, L., Wang, Y. and Chen, C., "What is LiFi?,” J. Light. Technol. 34(6), 1533-1544 (2016).

[2] Rajbhandari, S., McKendry, J. J. D., Herrnsdorf, J., Chun, H., Faulkner, G., Haas, H., Watson, I. M., O’Brien, D. and Dawson, M. D., "A review of gallium nitride LEDs for multi-gigabit-per-second visible light data communications," Semicond. Sci. Technol. 32(2), 23001 (2017). 
[3] McKendry, J. J. D., Green, R. P., Kelly, A. E., Gong, Z., Guilhabert, B., Massoubre, D., Gu, E. and Dawson, M. D., "High-Speed Visible Light Communications Using Individual Pixels in a Micro Light-Emitting Diode Array,” IEEE Photonics Technol. Lett. 22(18), 1346-1348 (2010).

[4] Ferreira, R. X. G., Xie, E., McKendry, J. J. D., Rajbhandari, S., Chun, H., Faulkner, G., Watson, S., Kelly, A. E., Gu, E., Penty, R. V., White, I. H., O’Brien, D. C. and Dawson, M. D., "High Bandwidth GaN-Based Micro-LEDs for Multi-Gb/s Visible Light Communications," IEEE Photonics Technol. Lett. 28(19), 2023-2026 (2016).

[5] Islim, M. S., Ferreira, R. X., He, X., Xie, E., Videv, S., Viola, S., Watson, S., Bamiedakis, N., Penty, R. V., White, I. H., Kelly, A. E., Gu, E., Haas, H. and Dawson, M. D., "Towards 10 Gb/s orthogonal frequency division multiplexing-based visible light communication using a GaN violet micro-LED," Photonics Res. 5(2), A35 (2017).

[6] Vinogradov, J., Kruglov, R., Engelbrecht, R., Ziemann, O., Sheu, J.-K., Chi, K.-L., Wun, J.-M. and Shi, J.-W., "GaN-Based Cyan Light-Emitting Diode with up to 1-GHz Bandwidth for High-Speed Transmission Over SI-POF," IEEE Photonics J. 9(3), 1-7 (2017).

[7] Dinh, D. V., Quan, Z., Roycroft, B., Parbrook, P. J. and Corbett, B., "GHz bandwidth semipolar $\left(112^{-}\right.$2) InGaN/GaN light-emitting diodes," Opt. Lett. 41(24), 5752 (2016).

[8] Rashidi, A., Monavarian, M., Aragon, A., Okur, S., Nami, M., Rishinaramangalam, A., Mishkat-U1Masabih, S. and Feezell, D., "High-Speed Nonpolar InGaN/GaN LEDs for Visible-Light Communication," IEEE Photonics Technol. Lett. 29(4), 381-384 (2017).

[9] Shen, C., Ng, T. K., Leonard, J. T., Pourhashemi, A., Nakamura, S., DenBaars, S. P., Speck, J. S., Alyamani, A. Y., El-desouki, M. M. and Ooi, B. S., "High-brightness semipolar (2021') blue InGaN/GaN superluminescent diodes for droop-free solid-state lighting and visible-light communications," Opt. Lett. 41(11), 2608 (2016).

[10] Cantore, M., Pfaff, N., Farrell, R. M., Speck, J. S., Nakamura, S. and DenBaars, S. P., "High luminous flux from single crystal phosphor-converted laser-based white lighting system," Opt. Express 24(2), A215 (2016).

[11] Watson, S., Tan, M., Najda, S. P., Perlin, P., Leszczynski, M., Targowski, G., Grzanka, S. and Kelly, A. E., "Visible light communications using a directly modulated $422 \mathrm{~nm}$ GaN laser diode," Opt. Lett. 38(19), 3792 (2013).

[12] Lee, C., Zhang, C., Cantore, M., Farrell, R. M., Oh, S. H., Margalith, T., Speck, J. S., Nakamura, S., Bowers, J. E. and DenBaars, S. P., "4 Gbps direct modulation of $450 \mathrm{~nm} \mathrm{GaN}$ laser for high-speed visible light communication," Opt. Express 23(12), 16232 (2015).

[13] Janjua, B., Oubei, H. M., Retamal, J. R. D., Ng, T. K., Tsai, C.-T., Wang, H.-Y., Chi, Y.-C., Kuo, H.C., Lin, G.-R., He, J.-H. and Ooi, B. S., "Going beyond 4 Gbps data rate by employing RGB laser diodes for visible light communication," Opt. Express 23(14), 18746 (2015).

[14] Tsonev, D., Videv, S. and Haas, H., "Towards a 100 Gb/s visible light wireless access network," Opt. Express 23(2), 1627 (2015).

[15] Lee, C., Shen, C., Oubei, H. M., Cantore, M., Janjua, B., Ng, T. K., Farrell, R. M., El-Desouki, M. M., Speck, J. S., Nakamura, S., Ooi, B. S. and DenBaars, S. P., "2 Gbit/s data transmission from an unfiltered laser-based phosphor-converted white lighting communication system," Opt. Express 23(23), 29779 (2015).

[16] Dursun, I., Shen, C., Parida, M. R., Pan, J., Sarmah, S. P., Priante, D., Alyami, N., Liu, J., Saidaminov, M. I., Alias, M. S., Abdelhady, A. L., Ng, T. K., Mohammed, O. F., Ooi, B. S. and Bakr, O. M., 
"Perovskite Nanocrystals as a Color Converter for Visible Light Communication," ACS Photonics 3(7), 1150-1156 (2016).

[17] Schubert, E. F., [Light-Emitting Diodes] (2006).

[18] David, A. and Grundmann, M. J., "Droop in InGaN light-emitting diodes: A differential carrier lifetime analysis," Appl. Phys. Lett. 96(10), 103504 (2010).

[19] Chen, C. H., Hargis, M., Woodall, J. M., Melloch, M. R., Reynolds, J. S., Yablonovitch, E. and Wang, W., "GHz bandwidth GaAs light-emitting diodes," Appl. Phys. Lett. 74(21), 3140 (1999).

[20] Coldren, L. A., Corzine, S. W. and Masanovic, M. L., [Diode Lasers and Photonic Integrated Circuits, 2nd ed.], John Wiley \& Sons, Inc., Hoboken, NJ, USA (2012).

[21] Yuan, Y., Brock, T., Bhattacharya, P., Caneau, C. and Bhat, R., "Edge-emitting lasers with shortperiod semiconductor/air distributed Bragg reflector mirrors," IEEE Photonics Technol. Lett. 9(7), 881-883 (1997).

[22] Matsui, Y., Murai, H., Arahira, S., Kutsuzawa, S. and Ogawa, Y., “30-GHz bandwidth 1.55- $\mu$ m straincompensated InGaAlAs-InGaAsP MQW laser,” IEEE Photonics Technol. Lett. 9(1), 25-27 (1997).

[23] Chichibu, S., Azuhata, T., Sota, T. and Nakamura, S., "Recombination of Localized Excitons in InGaN Single- and Multiquantum-Well Structures," MRS Proc. 449, 14-17 (1996).

[24] Masui, H., Sonoda, J., Pfaff, N., Koslow, I., Nakamura, S. and DenBaars, S. P., "Quantum-confined Stark effect on photoluminescence and electroluminescence characteristics of InGaN-based lightemitting diodes," J. Phys. D. Appl. Phys. 41(16), 165105 (2008).

[25] Scheibenzuber, W. G., Schwarz, U. T., Veprek, R. G., Witzigmann, B. and Hangleiter, A., "Calculation of optical eigenmodes and gain in semipolar and nonpolar InGaN/GaN laser diodes," Phys. Rev. B - Condens. Matter Mater. Phys. 80(11), 115320 (2009).

[26] Park, S.-H. and Ahn, D., "Nonpolar and semipolar GaN, optical gain and efficiency," Proc. SPIE 8625, Gall. Nitride Mater. Devices VIII, J.-I. Chyi, Y. Nanishi, H. Morkoç, J. Piprek, E. Yoon, and H. Fujioka, Eds., 862511, International Society for Optics and Photonics (2013).

[27] Kuritzky, L. Y. and Speck, J. S., "Lighting for the 21st century with laser diodes based on non-basal plane orientations of GaN," MRS Commun., 1-11 (2015).

[28] Schmidt, M. C., Kim, K.-C., Farrell, R. M., Feezell, D. F., Cohen, D. A., Saito, M., Fujito, K., Speck, J. S., DenBaars, S. P. and Nakamura, S., "Demonstration of Nonpolar $m$-Plane InGaN/GaN Laser Diodes,” Jpn. J. Appl. Phys. 46(No. 9), L190-L191 (2007).

[29] Farrell, R. M., Hsu, P. S., Haeger, D. A., Fujito, K., DenBaars, S. P., Speck, J. S. and Nakamura, S., "Low-threshold-current-density AlGaN-cladding-free m-plane InGaN/GaN laser diodes," Appl. Phys. Lett. 96(23), 231113 (2010).

[30] Pourhashemi, A., Farrell, R. M., Cohen, D. A., Speck, J. S., DenBaars, S. P. and Nakamura, S., "Highpower blue laser diodes with indium tin oxide cladding on semipolar $\left(202^{-} 1^{-}\right)$GaN substrates," Appl. Phys. Lett. 106(11), 111105 (2015).

[31] Becerra, D. L., Kuritzky, L. Y., Nedy, J., Abbas, A. S., Pourhashemi, A., Farrell, R. M., Cohen, D. A., Denbaars, S. P., Speck, J. S., Nakamura, S., Becerra, D. L., Kuritzky, L. Y., Nedy, J., Abbas, A. S., Speck, J. S. and Nakamura, S., "Measurement and analysis of internal loss and injection efficiency for continuous-wave blue semipolar $\left(202^{-} 1^{-}\right.$) III-nitride laser diodes with chemically assisted ion beam etched facets," Appl. Phys. Lett. 362(1999), 91106 (2016).

[32] Yonkee, B. P., Young, E. C., Lee, C., Leonard, J. T., DenBaars, S. P., Speck, J. S. and Nakamura, S., 
"Demonstration of a III-nitride edge-emitting laser diode utilizing a GaN tunnel junction contact," Opt. Express 24(7), 7816 (2016).

[33] Yonkee, B. P., Farrell, R. M., Leonard, J. T., DenBaars, S. P., Speck, J. S. and Nakamura, S., "Demonstration of low resistance ohmic contacts to p-type (2021) GaN," Semicond. Sci. Technol. 30(7), 75007 (2015).

[34] Rass, J., Wernicke, T., Kremzow, R., John, W., Einfeldt, S., Vogt, P., Weyers, M. and Kneissl, M., "Facet formation for laser diodes on nonpolar and semipolar GaN," Phys. status solidi 207(6), 13611364 (2010).

[35] Kuritzky, L. Y., Becerra, D. L., Abbas, A. S., Nedy, J., Nakamura, S., DenBaars, S. P. and Cohen, D. A., "Chemically assisted ion beam etching of laser diode facets on nonpolar and semipolar orientations of GaN," Semicond. Sci. Technol. 31(7), 75008 (2016).

[36] Wang, H., Kumagai, M., Tawara, T., Nishida, T., Akasaka, T., Kobayashi, N., Wang, H., Kumagai, M., Tawara, T. and Nishida, T., "Fabrication of an InGaN multiple-quantum-well laser diode featuring high reflectivity semiconductor/air distributed Bragg reflectors," Appl. Phys. Lett. 81(25), 4703-4705 (2002).

[37] Funato, M., Seok, Y., Yoshiaki, K., Akio, O., Yoichi, K., Takashi, K. and Nagahama, M. S., "Optical Gain Spectra of a (0001) InGaN Green Laser Diode,” Appl. Phys. Express 6(12), 122704 (2013).

[38] Banerjee, A., Frost, T., Stark, E. and Bhattacharya, P., "Continuous-wave operation and differential gain of InGaN/GaN quantum dot ridge waveguide lasers $(\lambda=420 \mathrm{~nm})$ on c-plane GaN substrate," Appl. Phys. Lett. 101(4), 41108 (2012).

[39] Frost, T., Banerjee, A. and Bhattacharya, P., "Small-signal modulation and differential gain of redemitting $(\lambda=630 \mathrm{~nm})$ InGaN/GaN quantum dot lasers," Appl. Phys. Lett. 103(21), 211111 (2013).

[40] Frost, T., Jahangir, S., Stark, E., Deshpande, S., Hazari, A., Zhao, C., Ooi, B. S. and Bhattacharya, P., "Monolithic Electrically Injected Nanowire Array Edge-Emitting Laser on (001) Silicon," Nano Lett. 14(8), 4535-4541 (2014).

[41] Melo, T., Hu, Y.-L., Weisbuch, C., Schmidt, M. C., David, A., Ellis, B., Poblenz, C., Lin, Y.-D., Krames, M. R. and Raring, J. W., "Gain comparison in polar and nonpolar/semipolar gallium-nitridebased laser diodes," Semicond. Sci. Technol. 27, 24015 (2012).

[42] Zhao, H., Arif, R. A., Ee, Y. K. and Tansu, N., "Optical gain analysis of strain-compensated InGaNAlGaN quantum well active regions for lasers emitting at 420-500 nm," Opt. Quantum Electron. 40, 301-306 (2008).

[43] Bowers, J. E., "High speed semiconductor laser design and performance," Solid. State. Electron. 30(1), 1-11 (1987).

[44] Lee, C., Zhang, C., Becerra, D. L., Lee, S., Forman, C. A., Oh, S. H., Farrell, R. M., Speck, J. S., Nakamura, S., Bowers, J. E. and DenBaars, S. P., "Dynamic characteristics of $410 \mathrm{~nm}$ semipolar $\left(202^{-} 1^{-}\right)$III-nitride laser diodes with a modulation bandwidth of over $5 \mathrm{GHz}$," Appl. Phys. Lett. 109(10), 101104 (2016).

[45] Denault, K. A., Cantore, M., Nakamura, S., DenBaars, S. P. and Seshadri, R., "Efficient and stable laser-driven white lighting," AIP Adv. 3(7), 72107 (2013).

[46] Cozzan, C., Brady, M. J., O ’Dea, N., Levin, E. E., Nakamura, S., DenBaars, S. P. and Seshadri, R., "Monolithic translucent BaMgAl 10 O 17 :Eu 2+ phosphors for laser-driven solid state lighting," AIP Adv. 6(10), 105005 (2016). 